\title{
Development of Novel Dynamic Drop-to-Drop Microextraction Coupled with GC-MS for the Trace Level Screening of Phenothiazine Drug in Human Biological Samples
}

\author{
Pratik Kumar Jagtap, Kavita Tapadia* \\ Department of Chemistry, National Institute of Technology, Raipur, CG, 492010, Chhattisgarh, INDIA.
}

\begin{abstract}
A novel analytical technique of dynamic drop-to-drop solvent microextraction (DDSME) is developed to determine phenothiazine drug promethazine commonly used in cough syrups and in aesthetic drinks, purple drank most common among youths. Here we apply coupling of highly sensitive technique of GC-MS with dynamic DDSME for the subnanomolar detection of promethazine drug from human biological samples (blood and urine). The method is a virtually solvent free and miniaturized version of traditional Liquidliquid microextraction (LLME), where the solvent to aqueous ratio is greatly reduced. The best optimum parameters for the dynamic DDSME technique were: extraction time of $10 \mathrm{~m}$, using 1-Octanol as the extraction organic solvent, volume of extraction solvent $3 \mu$, volume of donar aqueous phase $20 \mu \mathrm{l}$ and with no salt addition, the calibration range for dynamic DDSME is from 0.0 to $5.0 \mu \mathrm{g} \mathrm{ml}^{-1}$ with correlation coefficient $\left(\mathrm{R}^{2}\right)$ of $>0.984$. LOD for the drug was found to be $0.007 \mu \mathrm{g} / \mathrm{ml}$.
\end{abstract}

Key words: Dynamic DDSME, Mass-spectrometry, Pharmacokinetic studies, Promethazine, Optimization.

\section{INTRODUCTION}

Depression including adult hypertension is an important public-health challenge worldwide, thus priority should be given to aim at its determination of prevalence and prevention as a major health issue. ${ }^{1}$ Many types of antidepressant drugs have been used ever-since including TCAs (Tricyclic antidepressants) and other antipsychotic drugs thus, the determination of these drugs in human and animal biological fluids has always been a topic of interest for forensic pathologists and toxicologists. Promethazine is an antihistamine of phenothiazine family, it is a histamine H1-receptor antagonist. Literature review reveals its use in antimotion sickness, anti-emetic, anticholinergic and for its sedative effects.
Promethazine is a lipophillic drug freely soluble in water at $\mathrm{pH} \mathrm{5-7}$ with a $\mathrm{pKa}$ of 9.05. It is well absorbed from the gastrointestinal tract and also undergoes hepatic metabolism mainly to $\mathrm{N}$-desmethyl promethazine. Several method for the determination of promethazine in blood and urine samples have been reported such as nephelometric titrations, ${ }^{2}$ capillary electrophoresis and chemiluminescence, ${ }^{3}$ spectroanalytical methods, ${ }^{4}$ conductometricdetermination, ${ }^{5}$ advanced spectroscopic techniques, ${ }^{6}$ LC-MS, ${ }^{7,8}$ GC-MS ${ }^{9}$ and HPLC. ${ }^{10-11}$ Determination of antidepressants in blood, brain and hair tissues have also been reported using solid phase microextraction coupled with GC-MS. ${ }^{12}$
Submission Date: 18-03-2018; Revision Date: 14-08-2018; Accepted Date: 23-10-2018

DOI: 10.5530/ijper.52.4s.111 Correspondence: Dr. Kavita Tapadia, Department of Chemistry, National Institute of Technology, Raipur, CG, 492010, INDIA. Phone: +91-9977987702 E-mail: akavita9@rediffmail. com

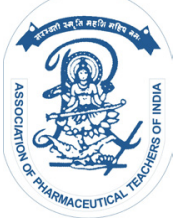

www.ijper.org 
Several microextraction techniques of sample preparation and extraction for drugs have been already reported but they suffer from various limitations for instance Single drop microextraction (SDME) is not used for sample preparation as it has poor reproducibility and also it results into instability of the solvent drop. ${ }^{13}$ Solid phase microextraction (SPME) suffers from the limitations like relatively expensive (fiber cost), limited time of fiber use, matrix effects and fiber damage. Liquidliquid extraction (LLE) involves several steps which may eventually lead to loss of analyte which can prove to affect the sensitivity and selectivity of the method specially in cases where the availability of sample is scarce. ${ }^{14}$ Thus, in order to overcome these limitations herein we developed a virtually solvent free, less time consuming method as compared to previously reported techniques of sample preparation. The method is based on the principle of enhanced diffusion of the target drug analyte from the aqueous phase to the organic phase, this potential for the mass transfer of the analyte is due to the concentration difference of the analyte between the two immiscible organic and aqueous phases and is given by the concentrations at equilibrium and at initial concentration.

$$
\mathrm{C} 1(\mathrm{PRO} / \mathrm{ORG}) \mathrm{Eq}=\mathrm{K} \mathrm{C}(\mathrm{PRO} / \mathrm{AQUEOUS}) \mathrm{Eq}
$$

Where, $\mathrm{C} 1=$ Concentration of Promethazine in organic phase at equillibrium

C2 $=$ Concentration of Promethazine in aqueous phase at equillibrium and $\mathrm{k}=$ distribution coefficient

Thus, there is an equilibrium established between the amount of the target drug analyte between the organic acceptor phase and circulating donar phase. Also the number of times the aspiration procedure is performed enhances the amount of analyte extracted. Here the rate determining step is often the process of transfer of analyte from the donar to the acceptor phase and hence subsequently determines the extraction efficiency. Also the dynamic drop to drop microextraction coupled to GC-MS is preferred and because it allows for the possibility of compound identification through commercially available libraries. Thus, the present work is needed and developed as an eco-compatible and cost efficient method for the trace level determination of promethazine in small amounts of sample solutions using novel dynamic drop-to drop microextraction method and its subsequent analysis using GC-MS technique.

\section{MATERIALS AND METHODS}

\section{Chemicals and reagents}

Analytical reagent grade methanol, chloroform, toluene, 1-Octanol and n-Hexane were obtained from SigmaAldrich (St. Louis, MO, USA). Pure drug samples were procured from Sigma-Aldrich (St. Louis, MO, USA). Stock solution of the drug was prepared in methanol with concentration of $1 \mathrm{mg} \mathrm{ml}^{-1}$. $\mathrm{pH}$ of the solution was adjusted using $0.1 \mathrm{~N} \mathrm{HCl}$ and $0.1 \mathrm{~N} \mathrm{NaOH}$ solutions and measured using digital pH meter (L1-617 ELICO, Hyderabad). Polyethylene vials with caps were used to collect blood samples from the patients undergoing treatment with Promethazine and were stored in refrigerator till the time of analysis. Chlorpromazine $\left(\mathrm{C}_{17} \mathrm{H}_{19} \mathrm{ClN}_{2} \mathrm{~S}\right.$ Mol. Mass - $\left.355.321 \mathrm{~g} \mathrm{~mol}^{-1}\right)$ was used as Internal standard (IS) based on structural similarities and fragmentation patterns.

\section{Dynamic drop to drop microextraction protocol}

The procedure was carried out in a $100 \mu \mathrm{l}$ vial with a PTFE (polytetrafluoroethylene) faced silicon septum and contains deionized water and blood sample separately. Aqueous sample of the target drug analyte was stirred at $300 \mathrm{rpm}$ for the enhanced transfer of the analyte from the aqueous to the organic phase. The microsyringe used for the extraction were of different tip configurations and according to the tip orifice we used different microsyringes like cone tip, bevel tip and blunt tip. The microsyringe was washed several times with the organic acceptor phase to remove any traces of moisture left in the microsyringe. 2-4 $\mu \mathrm{l}$ of the solvent is taken into a $10 \mu \mathrm{l}$ microsyringe with an angle cut tip and fixed into a clamp just above the vial for the easy movement of the organic solvent in and out of the microsyringe for the microextraction of the drug from the spiked deionized water and blood samples. $5.0 \mu \mathrm{l}$ of the aqueous solvent is withdrawn into the microsyringe held for $5.0 \mathrm{~s}$ for the extraction purpose and finally pushed back to the sample vial. ${ }^{15}$ This process is repeated several times until appropriate quantities of the drug has been extracted into the organic acceptor phase. Once a cycle of about 10-15 times has been performed the drug enriched organic acceptor phase is retracted back into the microsyringe and further injected into the inlet of GC-MS for further investigations. The details of the procedure for Dynamic drop to drop microextraction has been illustrated in Figure 1. The same syringe is used to introduce the drug enriched solvent into the GC-MS for the identification and quantification processes. ${ }^{16}$ 


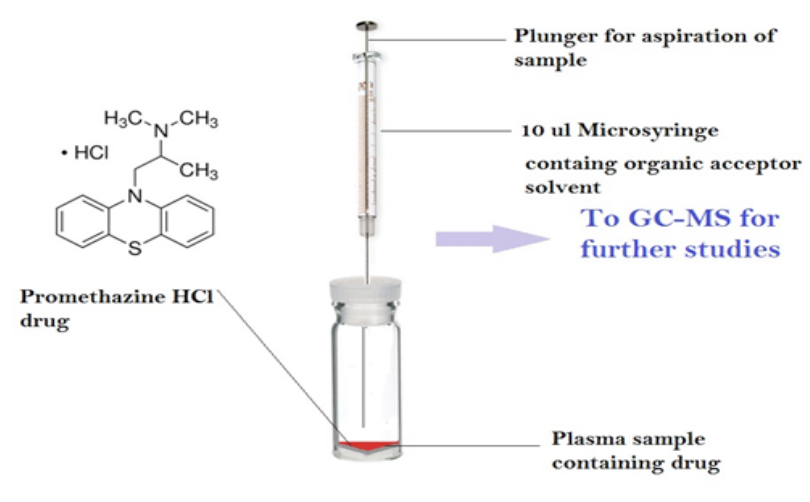

Figure 1: Schematic diagram for Dynamic DDSME procedure.

\section{GC-MS operating conditions}

A Thermo LTQ-XL GC-MS fitted with DB-5 capillary column (30m x 0.25mm x 1 micron) Supelco, Mississauga, ON, Canada was used for the analysis of the drug. The injection temperature was maintained at $250^{\circ} \mathrm{C}$ and the injection was made in the splitless mode. The initial oven temperature of the GC was kept at $80^{\circ} \mathrm{C}$ for $3 \mathrm{~m}$ and then programmed to increase to $250^{\circ} \mathrm{C}$ with increase of $20^{\circ} \mathrm{C}$ per minute and finally held for $3 \mathrm{~m}$. High purity He $(99.99 \%)$ was used as a carrier gas and flow rate set at $1.0 \mathrm{ml}$ per min. GC-MS under Electronic ionization in selective ion monitoring (SIM) was considered to obtain the spectra. The molecular ion peak was observed at $\mathrm{m} / \mathrm{z} 284.1$ and the other fragment ions were observed at $\mathrm{m} / \mathrm{z} 281.22,209.11$ and 147.20 as presented in Table 1. The mass range of detection for the mass spectrum was set between the range 50-400 Da.

\section{RESULTS}

\section{Optimization of the analytical parameters}

Various parameters affecting the extraction efficiency of the analyte drug is investigated for maximum efficiency for the present method. The effect of various param-

\begin{tabular}{|l|c|l|l|}
\hline \multicolumn{3}{|c|}{ Table 1: GC-MS peaks for Promethazine HCI } \\
\hline Drug & $\begin{array}{l}\text { Quantifier } \\
\text { ion } \mathrm{m} / \mathrm{z}\end{array}$ & $\begin{array}{l}\text { Qualifier ion } \\
\text { Retention time } \\
\text { (min) }\end{array}$ & $\begin{array}{l}\text { Retention } \\
\text { time (min) }\end{array}$ \\
\hline & & & $50(42.4)$ \\
Promethazine & 72.0 & $284.1,180.0,198.0$ & $68(57.6)$ \\
\hline
\end{tabular}

eters were used to identify and quantify the presence of the drug primarily in the human biological samples. ${ }^{17-19}$. Parameters affecting the extraction efficiency were investigated. Under optimal extraction conditions very high enrichment factor were achieved.

\section{a). Nature of extraction solvent}

The selection of the extraction solvent used should have low solubility in aqueous phase, high distribution coefficient and high chromatographic resolution, extractions were performed using several solvents like benzene, 1-octanol, xylene, toluene, $\mathrm{n}$-hexane and chloroform for appropriate extraction time and at $\mathrm{pH} 9.0$. The relative abundances of the peak obtained in GC-MS were maximum using 1-Octanol as solvent and hence it was used in subsequent experiments.

\section{b). Number of sampling cycles}

In dynamic DDSME technique with each aspiration cycle there was fresh transfer of the analyte from the donar to the acceptor phase thus, there was a linear relationship between the amount of the analyte extracted and the number of aspiration cycles. ${ }^{21}$ It was found that the extraction efficiency of the drug increases with increase in number of sampling cycles probably due to enhanced mass transfer of the drug from the donar (aqueous) to organic (acceptor) phase. For the present work 8-10 cycles of repeated aspirations were performed for $3 \mathrm{~m}$ extraction time to yield the desired level of extraction. Further increase in sampling volume has no influence in the extraction efficiency probably due to saturation of the organic acceptor phase with the drug.

\section{c).Volume of organic solvent}

High enrichment factor is achieved with high donar to acceptor volume ratio. In order to study the effect of the sampling volume of the extraction solvent, the volume was varied from 0.5 to $2.5 \mu \mathrm{l}$ for the extraction of the analyte. It was found that the extraction efficiency increases with increase in the sampling volumes of the acceptor phase for a fixed volume of donar phase probably due to increase in the amount of analyte with increasing solvent volumes as shown in Figure 2 (a). The relative abundances increases with increase in sampling volume from 0.5 to $2.5 \mu \mathrm{l}$ and then becomes almost constant due to attainment of equilibrium conditions and hence a sampling volume of $2.5 \mu \mathrm{l}$ was selected for the present investigation

\section{d). Volume of aqueous phase}

This is an important parameter which effects the extraction efficiency of the analyte and using larger volumes of the solvents better enrichment of the drug can be achieved which was not possible using previously reported methods. The volume of the aqueous phase 
a)

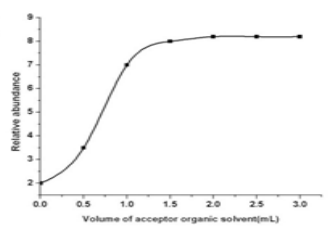

b)

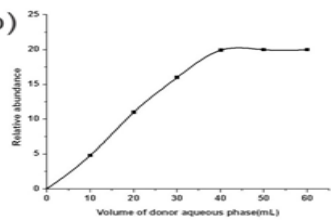

c)

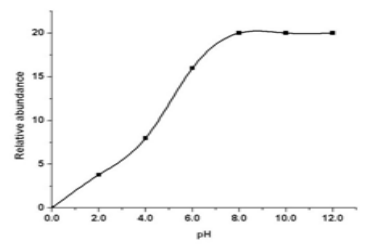

Figure 2: Optimization of analytical parameters a). Volume of acceptor solvent b). Volume of donar phase c). $\mathrm{pH}$.

was varied from 10 to $100 \mu \mathrm{l}$ and best extraction was obtained at $40 \mu \mathrm{l}$ and hence this volume was used for the present investigation shown in Figure 2 (b).

\section{e). Salt effect $(\mathrm{NaCl})$}

Prior to GC-MS analysis the effect of ionic strength by salt addition on the peak area in the GC-MS was also studies by the addition of the salt into the donar phase. The experiment was carried out by varying the concentration of salt from $0-10 \%(\mathrm{w} / \mathrm{v})$ in the donar phase, here the rate of transfer of analyte from the donar to the acceptor phase decreases which further interferes with the results of the dynamic DDSME procedure and hence all the investigations were performed in the absence of salt.

\section{f). Effect of $\mathrm{pH}$}

Promethazine is a basic drug with the pKa value of 9.05. The $\mathrm{pH}$ was adjusted using $0.1 \mathrm{~N} \mathrm{NaOH}$ and $0.1 \mathrm{~N}$ $\mathrm{HCl}$ to $8.5(<9.05)$. The relative abundances of the analyte drug increases with the increase in $\mathrm{pH}$ from 2 to 12 and higher extraction efficiency of the drug was achieved at $\mathrm{pH}$ of 10 , the results are shown in Figure 2 (c) and hence was selected as the optimum $\mathrm{pH}$ value for the present investigation. At $\mathrm{pH}$ lower than the pka value of the drug protonation occurs which affects the extraction efficiency and analysis results.

\section{g). Effect of stirring rate}

Agitation and stirring of the sample solution increases the rate of convection thus speeds up the mass transfer of the analyte drug from the sample solution to the acceptor solution. It was found that further increase in temperature beyond $60-65^{\circ} \mathrm{C}$ causes the microdrop to detach from the needle tip with $15.0 \mathrm{~m}$ of extraction time.

\section{DISCUSSION}

The method basically relies on the differential distribution of analytes between different phases at equilibrium. Here the sample analyte is mass transferred from the sample solution to the headspace microdrop of the acceptor phase. For studying the matrix effect of the microextraction procedure implemented, three replicate extractions were performed at the set optimal conditions in deionized water containing known quantities of the drug sample in the same linear range. The reason for better EF of the dynamic DDSME method is attributed due to enhanced rate of transfer of the drug from the donar to the acceptor phase. ${ }^{20}$ Also relative recoveries which is defined as the ratio of the concentration of the analyte in the biological sample to its concentration in the deionized water spiked with the same amount of the analyte has been found to be well within the limits. ${ }^{21}$

\section{Method validation}

The results obtained for the analysis of the drug in the blood samples is summarized in the Table 2. The sensitivity of the method was found to be satisfactory

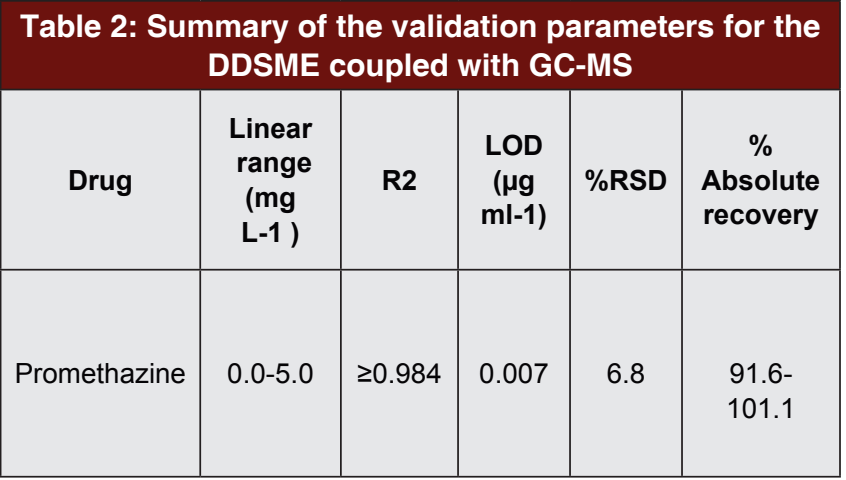

\section{Table 3: Comparison of the present method with} other method

\begin{tabular}{|c|c|c|c|c|c|c|}
\hline \multirow[b]{2}{*}{ Sample } & \multicolumn{3}{|c|}{$\begin{array}{c}\text { Dynamic } \\
\text { DDSME GCMS }\end{array}$} & \multicolumn{3}{|c|}{$\begin{array}{c}\text { Solvent } \\
\text { Extraction LCMS }\end{array}$} \\
\hline & 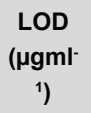 & 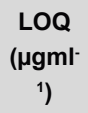 & $\begin{array}{l}\text { Linear } \\
\text { range } \\
\text { (mg/ml) }\end{array}$ & $\begin{array}{l}\text { LOD } \\
\left(\mu \operatorname{gml}^{-1}\right)\end{array}$ & 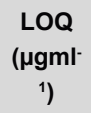 & $\begin{array}{c}\text { Linear } \\
\text { range } \\
(\mathrm{mg} / \mathrm{ml})\end{array}$ \\
\hline $\begin{array}{l}\text { Deionized } \\
\text { water }\end{array}$ & 0.007 & 10.41 & $0.5-2.5$ & 0.009 & 13.3 & $0.05-0.3$ \\
\hline Urine & 0.009 & 13.47 & & NR & NR & \\
\hline Blood & 0.024 & 22.62 & & NR & NR & \\
\hline
\end{tabular}


in terms of LOD and LOQ values. The selectivity was analyzed in terms of the plots between the peak areas vs the drug concentration. The linearity of the drug was measured in the range of 0.0 to $2.5 \mu \mathrm{g} \mathrm{ml}^{-1}$. Also the analysis of the linearity range complies with the guidance for industrial and bioanalytical method validation. ${ }^{22}$ The precision of the results obtained was measured in terms of repeatability was also well within the range.

\section{Application of the proposed method to real biological samples for pharmacokinetic studies}

The obtained parameters for the efficient extraction of the drug was further extended to real blood sample of the patients following the course of treatment with the Promethazine drug. We collected the blank blood sample (without drug) before the onset of the treatment and consequently patient was given a $10 \mathrm{mg}$ tablet of Promethazine for the first night and blood samples were collected after $4 \mathrm{~h}$ and after $8 \mathrm{~h}$ after informed consent has been obtained from the participants involved. The signal of the drug was obtained at a given retention time after GC-MS analysis and the signal peak was not changed due to the matrix effects of the other drugs and also doesn't involve the interferences due to other biological matrices.

\section{CONCLUSION}

Enrichment factor (EF) is defined as the final concentration of the analyte in the organic acceptor phase before GC-MS procedure to its initial concentration in the donar aqueous phase. Various parameters affecting the extraction efficiency were investigated and it was observed that under optimal extraction conditions very high enrichment of the drug was achieved compared to other methods as shown in Table 3. Thus, the method is simple and found to exhibit high EF as compared to static DDSME technique. It is believed that the present method can be extended for the extraction and preconcentration of the drug of interest from mixed drug and also from more complex matrices. The method can also be applied for the screening of the toxicological assays in forensic samples and in cases of drug over dosage. Work is in progress to apply such procedures to more complex forensic sample matrices. Thus, the method has emerged as an easily implementable micro level sample cleanup and preconcentration technique. Although the present method has a high accuracy and reproducibility but for large number of samples especially in forensic laboratories, automation of the dynamic DDSME can be performed using computer controlled auto samplers. The advantages of automation would be improved precision, increased sample throughput and unattended operations which basically reduces the extraction time and thus enhances the rapidity of the technique in clinical laboratories. Sensitivity can be adjusted over a wide range by changing the sampling period, sampling volume or even number of samplings.

\section{ACKNOWLEDGEMENT}

The Authors are thankful To National Institute of Technology, Raipur for providing all the necessary facilities, and also Central Instrumentation Laboratory NIPER Mohali India for the GC-MS facility.

\section{CONFLICT OF INTEREST}

The author declare that there is no conflict of interest.

\section{ABBREVIATIONS}

DDSME: Dynamic drop-to drop solvent microextraction; LLME: Liquid-liquid microextraction; LOD: Limit of detection; SDME : Single drop microextraction; EF: Extraction effeciency.

\section{ETHICAL CONDUCT OF RESEARCH}

The authors state that they have obtained appropriate institutional review board approval or have followed the principles outlined in the Declaration of Helsinki for all human or animal experimental investigations.

\section{REFERENCES}

1. Kearney PM, Whelton M, Reynolds K, Muntner P, Whelton PK, He J, et al. Global burden of hypertension: analysis of worldwide data. Lancet. 2005;365(9455):217-23.

2. Zhang Q, Zhan X, Li C, Lin T, Li L, Yin X, et al. Determination of promethazine hydrochloride and its preparations by highly accurate nephelometric titration. Int $\mathrm{J}$ of Pharm. 2005;302(1-2):10-7.

3. Francisco J, Lara AM, García-Campaña, Gámiz-Gracia L, Juan M, et al. Determination of phenothiazines in pharmaceutical formulations and human urine using capillary electrophoresis with chemiluminescence detection. Electrophoresis. 2006;27(12):2348-59.

4. Daniel D, Gutz IGR. Flow injection spectroelectroanalytical method for determination of promethazine hydrochloride in pharmaceutical preparations. Anal Chim Acta. 2003;494(1-2):215-24. 
5. Issa YM, El-Hawary WF, Ahmed AF. Ion pair formation in pharmaceutical analysis. Conductimetric determination of promazine, chloropromazine, promethazine, imipramine and cipro- floxacin hydrochlorides in pure form, drug formulations and urine. Michrochim Acta. 2000;134(1-2):9-14.

6. Rama MJR, Mrdina AR, Dı'az AM. Bead injection spectroscopy-flow injection analysis. (BIS-FIA): An interesting tool applicable to pharmaceutical analysis: Determination of promethazine and trifluperazine. J Pharm Biomed Anal. 2004;35(5):1027-34.

7. Sreenivasa RV, Sivarama P, Kambhampati LP, David WA, Bourne A. Liquid Chromatographic Method for the Simultaneous Determination of Promethazine and Three of Its Metabolites in Blood Using Electrochemical and UV Detectors. J Chromatogr Sci. 2001;39(2):70-2.

8. Liu P, Liang S, Wang BJ, Guo RC. Development and validation of a sensitive method for the determination of Promethazine chloride in human blood and urine. Eur J Drug Metab Ph. 2009;34(3):177-84.

9. Papoutsis I, Khraiwesh A, Nikolaou P, Pistos C, Spiliopoulou C, Athanaselis $S$, et al. A fully validated method for the simultenous determination of 11 antidepressant drugs in whole blood by gas chromatography-mass spectrometry. J Pharmaceut Biomed. 2012;70:557-62.

10. Huang M, Gao JY, Zhai ZG, Liang QL, Wang YM, Qiang BY, et al. An HPLCESI-MS method for simultaneous determination of fourteen metabolites of promethazine and caffeine and its application to pharmacokinetic study of the combination therapy against motion sickness. J Pharmaceut Biomed. 2012;62(25):119-28.

11. Miyabayashi T, Yamashita K, Aoki I, Motohashi M, Yashiki T, Yatani K, et al. Determination of manidipine and its pyridine metabolite in human serum by high-performance liquid chromatography with ultraviolet detection and column switching. J Chromatogr. 1989;494:209-17.

12. Wille SMR, Letter EAD, Piette MHA, Overschelde LKV, Petegham CHV, Lambert WE, et al. Determination of antidepressants in human postmortem blood, brain tissue and hair using gas chromatography-mass spectrometry. Int J Legal Med. 2009;123(6):451-8.
13. Jeannot MA, Przyjazny A, Kokosa JM. Single drop microextractiondevelopment, applications and future trends. J Chromatogr A. 2010;1217(16):2326-36.

14. Psillakis E, Kalogerakis N. Developments in single-drop microextraction. Trends Anal Chem. 2002;21(1).

15. Shrivas K, Wu HF. Quantitative bioanalysis of quinine by atmospheric pressure-matrix assisted laser desorption/ ionization mass apectrometry combined with dynamic drop-todrop solvent microextraction. Anal Chim Acta. 2007;605(2):153-8.

16. Jagtap PK, Tapadia K. Green chemistry an ecocompatible approach for the nanodrop spectrophotometric determination of amitriptyline in pure and pharmaceutical dosage forms. Rasa. J Chem. 2016;9(4):582-7.

17. Agrawal K, Wu HF. Drop-to-drop solvent microextraction coupled with gas chromatography/mass spectrometry for rapid determination of trimeprazine in urine and blood of rats: application to pharmacokinetic studies. Rapid Commun Mass Spectrom. 2007;21(20):3352-6.

18. Tapadia K, Shrivas K, Upadhyay LSB. GC-MS coupled with hollow fiber drop-to-drop microextraction for the determination of antidepressants drugs in human blood sample. Chromatographia. 2011;74(5-6):437-42.

19. Jagtap PK, Tapadia K. Pharmacokinetic determination and analysis of nortriptyline based on GC-MS coupled with hollow-fiber drop-to-drop solvent microextraction technique. Bioanalysis. 2018;10(3):143-52.

20. Kailasa SK, Wu HF. Single drop microextraction for bioanalysis: present and future. Bioanalysis. 2013;5(21).

21. Amin SS, Zeynali KA, Khoubnasabjafari M, Rashidi F, Jouyban A. Development and validation of ultrasound assisted and dispersive liquidliquid microextraction combined with HPLC-UV method for determination of Bosentan in human plasma and urine samples. J Braz Chem Soc. 2017;28(5).

22. He Y. Microextraction and its application to forensic toxicological analysis. LCGC. 2017;35(1):14-20.

\section{PICTORIAL ABSTRACT}

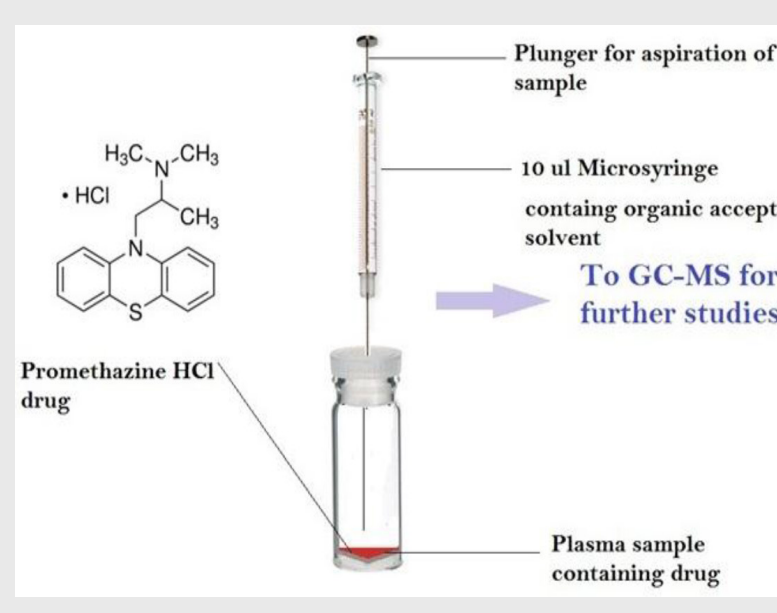

\section{Summary}

The method of Dynamic drop to drop microextraction coupled with GC-MS proves to be a selective and sensitive method for the trace level determination of Promethazine in small quantities of biological samples. The method stands out among other previously reported methods due to its low LOD values for the drug even in complex matrices. The present method exhibits good relative recoveries and hence better extraction efficiency with short analysis time without derivatization.

Cite this article: Jagtap PK, Tapadia K. Development of Novel Dynamic Drop-to-Drop Microextraction Coupled with GC-MS for the Trace Level Screening of Phenothiazine Drug in Human Plasma Samples. Indian J of Pharmaceutical Education and Research. 2018;52(4 Suppl 2):s303-s308. 